\title{
CLIMATIC WARMING, GLACIERS AND SEA LEVEL
}

\author{
(Abstract) \\ by \\ R.M. Koerner \\ (Geological Survey of Canada, Ottawa, K1A 0E4, Canada) \\ and \\ D.A. Fisher
}

(Geophysical Institute, Department of Glaciology, University of Copenhagen, Denmark)

\begin{abstract}
The modern concensus outside of the glaciological community is that "greenhouse" gases, released by human activity, will cause an unprecedented temperature rise over the next 100 years and thereby cause a socially-threatening rise of sea level. With respect to ice the concept is simple: warmer means less. The relationship between glaciers and climate is much more complex than this. Warmer also means more vapour transport and there is ample evidence from both theory and ice-core data that snow accumulation rates in both Greenland and Antarctica were lower during the last glacial period. The problem is whether the increased accumulation rates will be exceeded by increased melting of ice in the ablation areas. Antarctica could play a dominant role because of its size and very low temperatures. Only a small percent of Antarctica will increase its meltwater runoff into the ocean. Furthermore, its dynamic response time is so large that the calving rate will not change over a 200-year period. Most of the increased melt will be absorbed in the firn and the question is how much the snow accumulation rate will increase over the major part of the continent.
\end{abstract}

In the northern hemisphere one has to consider the way in which the warming will manifest itself seasonally. Most of the "forecasts" indicate that most of the warming will occur in the winter rather than the summer. In this case one has to consider the balance between greatly increased winter snowfall rates and only slightly increased summer melt rates. In this respect a review of the snow accumulation and ice melt rates from different glaciers and ice caps in the Canadian Arctic Islands is pertinent. Over the past 20 to 30 years we see no sign of a trend of either side of the balance equation (accumulation, melt). Is this the effect of high noise levels or is there simply no trend?

Finally, we review the ground-ice potential in terms of sea-level change. Ground ice may not form a large part of the world's ice reserves but it covers a large area. Both increased snowfall rates in winter, and summer warming will move to increase the thickness of the active layer. This will result in run-off to the oceans.

Global circulation models might be modified to determine a "best guess" of future sea-level change. To do this they must incorporate all of the parameters considered in this paper.

\section{PAST TEMPERATURE RECORD FROM THE ANALYSIS OF MELT FEATURES IN THE DYE 3, GREENLAND, ICE CORE \\ (Abstract)}

by

Chester C. Langway, Jr. and Hitoshi Shoji

(Ice Core Laboratory, Department of Geology, State University of New York at Buffalo, 4240 Ridge

Lea Road, Amherst, NY 14226, U.S.A.)

The layered sequences of melt features preserved in inland polar ice sheets provide valuable proxy data on past variations in summer temperature. A continuous detailed light-table examination was made on the $2037 \mathrm{~m}$-deep Dye 3 ice core immediately after core recovery. Melt features are products of high air temperatures or solar insolation which occur only at or near the snow surface during summer months. A correlation is made between these features and the extent and intensity of summer temperatures. Care must be exercised to identify and distinguish between all mm-thick radiation crusts and wind crusts contained in the record. The absence or presence of these discrete features serve respectively as indicators of total summer cloud cover and the extent of winter storm activity although they are difficult to differentiate from only light-table observations. In this analysis both thin radiation crusts and wind crusts are not in themselves significant indicators of long-term temperature trends, but may serve as incipient subsurface horizons or barrier crusts for the formation of thicker ice melt features caused by downward melt percolation during elevated surface temperature conditions.

More than 10000 individual melt features, including ice layers, ice lenses and ice wedges (but excluding ice glands) 